\title{
Anorectal contractility under basal conditions and during rectal infusion of saline in ulcerative colitis
}

\author{
S S C RAO, N W READ, J A H STOBART, W G HAYNES, S BENJAMIN, \\ AND C D HOLDSWORTH \\ From the Sub-Department of Human Gastrointestinal Physiology and Nutrition, Royal Hallamshire Hospital, \\ Sheffield
}

SUMMARY Pressure activity in the rectum and anal canal was measured with a multilumen probe in 29 patients with ulcerative colitis (12 active, 11 quiescent, six studied during both phases) and 18 normal controls under resting conditions and during rectal infusion of saline. Resting motor activity was significantly decreased in patients with active colitis compared with quiescent colitis $(\mathbf{p}<0 \cdot 005)$ and normal controls $(\mathbf{p}<\mathbf{0 \cdot 0 0 1})$. Forty per cent of active colitics showed a featureless record compared with only one patient with quiescent colitis and one normal subject. The volume of saline infused before leakage occurred, and the total volume retained were significantly lower $(\mathbf{p}<0 \cdot 001)$ in patients with active and quiescent colitis compared with normal controls. Rectal infusion of saline provoked regular rectal contractions, of significantly higher $(\mathbf{p}<0 \cdot 05)$ amplitude in patients with active colitis, than in quiescent colitis or controls. These rectal contractions were associated with simultaneous anal relaxations. During saline infusion, peak anal pressures were lower in patients with ulcerative colitis than in normal subjects, but there were no significant differences in relaxation pressures. In normal subjects, the rectal pressures remained below the anal pressures throughout the saline infusion. Peak rectal pressures exceeded the anal relaxation pressures during the last five minutes of saline infusion in patients with ulcerative colitis and throughout the infusion in those patients who complained of incontinence. Results suggest that although the resting rectal motor activity is diminished in patients with ulcerative colitis, luminal distension causes the inflamed rectum to generate abnormally strong contractions that may threaten continence.

Previous measurements of the pressure activity of the anorectum in patients with ulcerative colitis have shown conflicting results. Chaudhary and Truelove' measured intraluminal pressures under basal conditions, by using three open tip catheters situated at $7 \cdot 5,15$, and $22.5 \mathrm{~cm}$ from the anal verge, and reported increased rectosigmoid contractility in 15 patients with moderately severe colitis. Connell' used three miniature balloons $(7 \mathrm{~mm} \times 10 \mathrm{~mm})$ situated at 10,15 , and $20 \mathrm{~cm}$ from the anal verge and described reduced contractility in three patients with active colitis. Other workers have used a tandem balloon

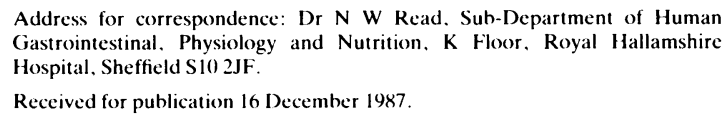

Address for correspondence: Dr N W Read, Sub-Department of Human Gastrointestinal. Physiology and Nutrition, K Floor, Royal Hallamshire Hospital, Sheffield S10 2JF.

Received for publication 16 December 1987.

system consisting of two targe balloons $(4.5 \times 3 \times 3$ $\mathrm{cm}$ ) centred at 18 and $8 \mathrm{~cm}$ from the anal margin, and showed that active colitics have a diminished total activity, but an increased incidence of large propulsive waves. ${ }^{3+}$ Davidson and colleagues ${ }^{56}$ used open tip catheters to record intraluminal pressures in the sigmoid, rectosigmoid and upper and lower rectum in children with colitis, and described large propulsive waves which were similar to those reported in adult colitics, ${ }^{3+}$ but they interpreted these waves as a feature of the diarrhoeal state and not of ulcerative colitis per se. Our previous studies have shown that patients with ulcerative colitis have a hypersensitive rectum that reacts excessively to balloon distension, ${ }^{7}$ but that basal and squeeze sphincter pressures were normal. 
The discrepancies in the results from different studies may reflect differences in either the design of the pressure sensors or in the recording sites as well as differences in patient selection. Intraluminal pressures at different sites in the colon can vary quite considerably ${ }^{\star 11}$ and recordings may need to be made simultaneously at multiple sites to gain a clear impression of rectosigmoid contractility. Results may also differ after stimulation such as eating a meal." "I"

The aim of this study was to investigate the integrated pressure activity of the rectum and anus, in patients with ulcerative colitis and normal controls, under basal conditions and during provocation by rectal infusion of a large volume of fluid..$^{12}$

\section{Methods}

\section{SUBJECTS}

These were 29 patients with histologically diagnosed ulcerative colitis, categorised on the basis of activity and severity using Truelove and Witts criteria. ${ }^{1+}$ Eleven patients had quiescent disease at the time of study, six patients had mild colitis, 10 had moderately severe colitis (six of whom complained of episodes of incontinence) and two had severe colitis. Studies were carried out in six patients during active and quiescent phases of colitis. Other clinical details are shown in Table 1. Patients were excluded from the study if they were severely ill, had hypokalemia, had undergone anorectal surgery or trauma or were taking opiates, anticholinergic agents, or stool bulking preparations. No medication was taken on the morning of the study day, but patients continued to take their prescribed medication of either sulphasalazine and/or oral prednisolone sulphate and/or rectal steroids until that time. Tests were also carried out on nine normal men and nine normal women who had no history of anorectal or other medical disorders.

\section{ETHICAL CONSIDERATIONS}

The study was approved by the Ethical Committee of the Sheffield Health Authority (Teaching) in June, 1986. All subjects gave written informed consent for the study to be carried out.

\section{STUDY PROTOCOL.}

All subjects fasted for at least 12 hours before the test and were advised to empty their bowels before the study. No bowel preparation was used in order to avoid the effects of cleansing the bowel on basal

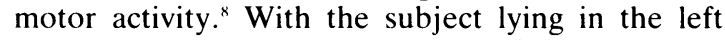
lateral position, a multilumen probe (length $=20 \mathrm{~cm}$, external diameter $=4 \mathrm{~mm}$ ) with eight side holes was inserted under direct vision through a sigmoidoscope. This examination also provided an oppor-
Table 1 Details of normal controls and patients with ulcerative colitis

\begin{tabular}{lcll}
\hline & & \multicolumn{2}{l}{ Ulcerative colitis } \\
\cline { 3 - 4 } & Controls & Active & Quiescent \\
\hline Number & 18 & 18 & 17 \\
Sex $(\mathrm{M} / \mathrm{F})$ & $9 / 9$ & $11 / 7$ & $9 / 8$ \\
Number with total colitis & - & 7 & 6 \\
Number with distal colitis & - & 11 & 11 \\
$\begin{array}{l}\text { Median age (yr) (range) } \\
\text { Median duration of colitis (yr) }\end{array}$ & $-35(20-65)$ & $40(23-77)$ & $44(26-74)$ \\
Median stool frequency/day & $1(0 \cdot 5-2)$ & $6(0 \cdot 5-27)$ & $7(0 \cdot 6-27)$ \\
(range) & & & \\
\hline
\end{tabular}

*significantly different from quiescent colitis and controls $\mathrm{p}<() \cdot() 1$.

tunity to assess the state of the mucosa. When correctly positioned, the eight side holes were located at $0 \cdot 5,1,2,6,9,12,15$, and $18 \mathrm{~cm}$ from the anal verge. Each side hole was perfused with water at a rate of $0.2 \mathrm{ml} / \mathrm{min}$ using a low compliance perfusion apparatus (Arndorfer, Milwaukee, USA) and intraluminal pressures were measured by pressure transducers (Gould Electronics Ltd, Coventry, UK) situated within each infusion line and connected via amplifiers to an eight channel chart recorder (Type 7758A, Hewlett-Packard Co, Waltham, Mass, USA). The pressure records were zeroed before tube insertion by holding the pressure catheter horizontally at the level of the anus. This manoeuvre was repeated after the test to check for baseline drift. Intraluminal pressures were recorded continuously for 60 minutes while subjects read or listened to music and kept as still as possible.

After the basal recording, a narrow single lumen soft polyvinyl tube (external diameter $=2 \mathrm{~mm}$ ) was inserted $8 \mathrm{~cm}$ into the rectum alongside the multilumen probe, already in situ. The subjects were moved to a special chair ${ }^{12}$ and $1500 \mathrm{ml}$ normal saline solution, warmed to $37^{\circ} \mathrm{C}$, was infused into the rectum at a constant rate of $60 \mathrm{ml} / \mathrm{min} .^{13}$ Subjects were instructed to retain the fluid for as long as possible and any leakage of fluid was collected through a funnel and a graduated cylinder placed under the seat. The volume infused at the time of initial leak (defined as a leak of at least $10 \mathrm{ml}$ ), and the total volume retained after completion of infusion were recorded.

\section{MEASUREMENTS}

\section{Anorectal pressure under basal conditions}

The manometric records were analysed to determine the rate of occurrence, frequency, amplitude, and pattern of pressure waves. A fluctuation in anal and rectal pressure was considered as a contraction if its amplitude was greater than $5 \mathrm{mmHg}$ and its duration 
was at least five seconds. The pattern of rectal contractions (whether isolated or rhythmic) was noted and the percentage of the total recording time occupied by these contractions was calculated by expressing the duration of contractions in all rectal channels as a percentage of the total length of rectal record. Pressure waves that occurred within five seconds at more than three adjacent sites in the rectum were termed coordinated contractions, and their relationship to anal relaxations were noted. Artefacts caused by coughing and straining were marked on the record and were excluded from analysis. Anal slow and ultraslow waves were scored according to previously published criteria. ${ }^{15}$

Responses to rectal infusion of saline

In all subjects tested, infusion of saline induced regular rectal contractions, that occurred at the same time as anal relaxations. The average basal and the average peak pressures of the rectal contractions (9 $\mathrm{cm}$ port), the average peak and relaxation pressures of the anal oscillations $(2 \mathrm{~cm}$ port $)$ and the frequency of oscillations in the rectum were analysed during sequential five minute periods using previously published criteria. ${ }^{12}$

STATISTICAL ANALYSIS

The degree of significance between data from patients with active and quiescent colitis and from normal subjects were calculated using paired or unpaired Student's $t$ test, whichever was appropriate. The differences in the stool frequency were analysed using Wilcoxon's rank-sum test.

\section{Results}

\section{BASAL RECORDING}

\section{Anal pressure fluctuations}

The anal pressure profiles consisted of slow waves with a frequency of $8-16 /$ min observed in all groups of subjects, and ultraslow waves with a frequency of $0 \cdot 8-1 \cdot 2 / \mathrm{min}$, observed in five of $18(28 \%)$ patients with active colitis, six of $17(35 \%)$ patients with quiescent colitis and six of $18(34 \%)$ normal controls. There were no significant differences between patients with active and quiescent colitis and normal controls in the frequency $(11(2) v 12(3) v 14(4) / \mathrm{min}$, mean (SD)) and the amplitude (10 (5) $v 11$ (5) $v 11$ (3) $\mathrm{mmHg}$, mean (SD)) of slow waves or in the frequency $(1.2(0.3) \vee 1.1(0.1) \vee 1.3(0.5) / \mathrm{min})$ and amplitude (41 (11) $v 51$ (8) $v 41(5) \mathrm{mmHg})$ of ultraslow waves.

Rectal contractions

Resting pressure records in colitics and controls
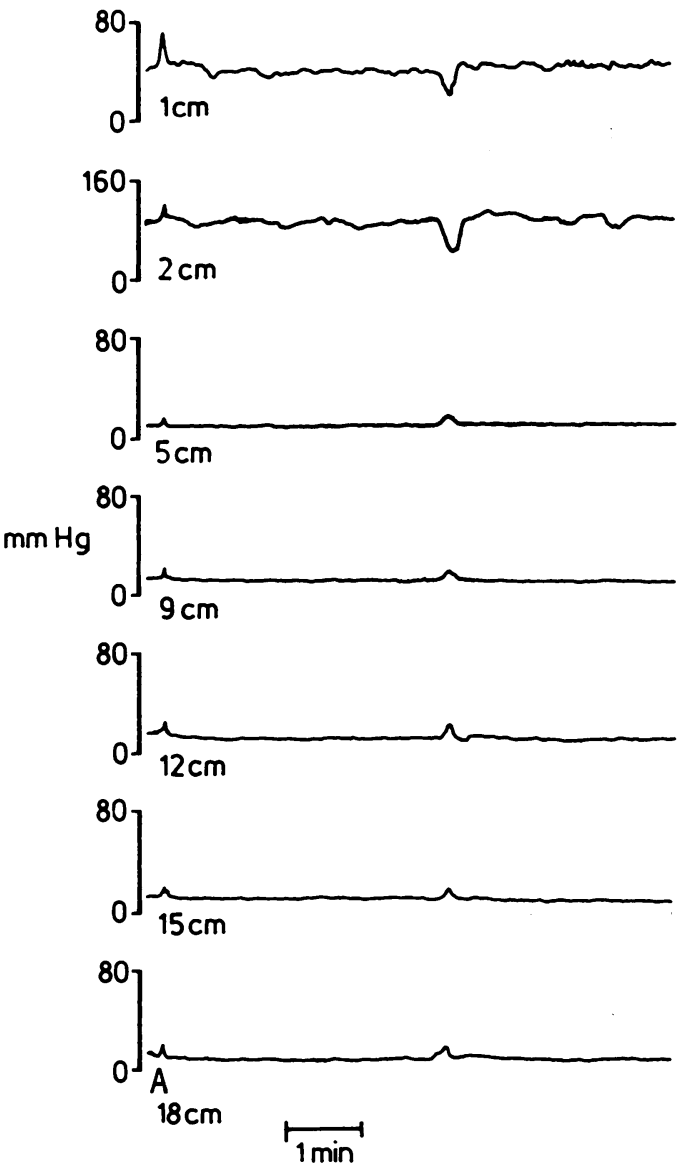

Fig. 1 Resting pattern of pressure activity in channels located in the rectosigmoid region and anal canal showing a typical example of an isolated and coordinated rectal contraction associated with anal relaxation in a patient with colitis. 'A' represents an artefact.

consisted of isolated contractions (Fig. 1), that were often associated with anal relaxations, and rhythmic contractions that occurred in irregular periods interspersed with periods of complete quiescence (Fig. 2). The pattern of the pressure activity showed considerable variation between subjects and between different sites and at different times in the same subject. The percentage of the total recording time during which contractions were recorded in any of the rectal channels was lower in active colitics $(12 \%)$ than in either quiescent colitics $(30 \%, p<0.005)$ or normal controls $(37 \%, p<0.001)$. Forty per cent of patients with active colitis showed no phasic contractions in any of the rectal channels during the one hour basal recording. Only one quiescent colitic and one normal subject showed a similar flat record. The site incid- 

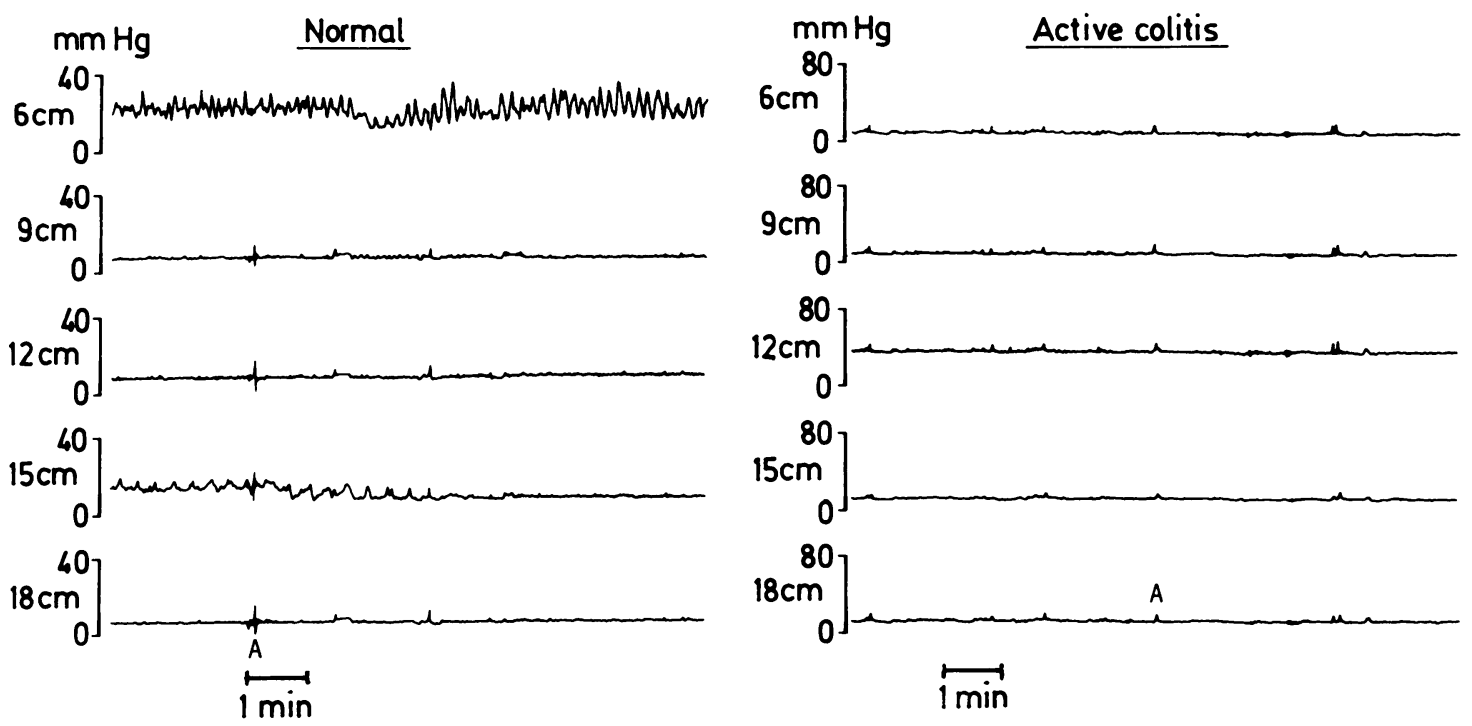

Fig. 2 Typical patterns of the resting pressure activity in the rectosigmoid channels at different distances from the anal verge, in a normal subject and in a patient with active colitis. 'A' represents artefacts.

ence and frequency characteristics of the rectal contractions from the different groups are summarised in Table 2.

Table 2 Patterns of basal motor activity in the rectosigmoid channels in normal controls and in patients with active and quiescent ulcerative colitis

\begin{tabular}{|c|c|c|c|}
\hline & \multirow[b]{2}{*}{$\begin{array}{l}\text { Normal } \\
(n=18)\end{array}$} & \multicolumn{2}{|c|}{ Ulcerative colitis } \\
\hline & & $\begin{array}{l}\text { Active } \\
(n=18)\end{array}$ & $\begin{array}{l}\text { Quiescent } \\
(n=17)\end{array}$ \\
\hline $\begin{array}{l}\text { Duration of basal motor activity (\% of } \\
\text { recording time) (mean (SD) })^{\dagger}\end{array}$ & $37(18)$ & $12(12)^{*}$ & $30(18)$ \\
\hline \multicolumn{4}{|c|}{ Subjects with rhythmic contractions (n) } \\
\hline In one channel & $17[94]$ & $11[61]$ & $16[94]$ \\
\hline $\begin{array}{l}\text { In two adjacent channels with similar } \\
\text { frequency }\end{array}$ & $9[50 \mid$ & $6[33]$ & $6[35]$ \\
\hline $\begin{array}{l}\text { In two non-adjacent channels with } \\
\text { similar frequency }\end{array}$ & $5[27]$ & $2[11]$ & $9[53]$ \\
\hline Occurring at $2 \cdot 5-4 \mathrm{cycle} / \mathrm{min}$ & $17[94]$ & $9[50]$ & $13[76]$ \\
\hline Occurring at $5-8$ cycle $/ \mathrm{min}$ & $6[33]$ & $7[39]$ & $9[53]$ \\
\hline $\begin{array}{l}\text { Occurring simultaneously at different } \\
\text { sites with two different frequencies }\end{array}$ & $5[27]$ & $3[17]$ & $7[42]$ \\
\hline \multicolumn{4}{|l|}{ Isolated contractions } \\
\hline $\begin{array}{l}\text { Subjects showing isolated contractions } \\
\text { (n) }\end{array}$ & $17[94]$ & $11[61]$ & $16(94)$ \\
\hline $\begin{array}{l}\text { Total number of contractions observed } \\
\text { during the one hour recording } \dagger\end{array}$ & 66 & 33 & 63 \\
\hline $\begin{array}{l}\text { Number of isolated contractions } \\
\text { associated with anal relaxation } \dagger\end{array}$ & $55[92]$ & $27[82]$ & $52[82]$ \\
\hline
\end{tabular}

* Significantly different from quiescent colitis and normal subjects, $p<0.005 ; †$ Except where indicated the results are expressed as the number of subjects with the percentages of the total group in square brackets.
Rhythmic contractions never occurred in all the channels simultaneously and could occur at different frequencies in different channels at the same time (Table 2). The frequency of the rectal contractions never corresponded with the frequencies of anal slow or ultraslow waves. The duration of rhythmic activity varied from 2 to 40 minutes. The amplitude of contractions varied between 5 and $38 \mathrm{mmHg}$ and the frequency between 2.5 and 8 cycles $/ \mathrm{min}$, and there were no differences between the groups in the average amplitude and frequency of contractions.

Isolated contractions were observed in a lower proportion of patients with active colitis compared with quiescent colitics and controls, but the percentage of contractions that were associated with anal relaxations were similar in the three groups (Table 2). Large amplitude propagated contractions ${ }^{25}$ and pressure waves with a duration greater than 30 seconds ${ }^{1}$ were not seen in any of our recordings.

\section{Rectal infusion of saline}

The volume of saline that had been infused into the rectum when leakage first occurred and the total volume retained were both significantly lower in patients with active colitis $(\mathrm{p}<0.001)$ and quiescent colitis $(p<0.001)$ compared with normal controls (Table 3). There were no significant differences in these volumes between patients with active and quiescent disease. Among patients with active colitis, those with moderately severe colitis leaked saline after infusion of a smaller volume (439 (568) v 892 $(462) \mathrm{ml}$, mean $(\mathrm{SD}), \mathrm{p}<0 \cdot 05)$ and retained less fluid 
Table 3 Results of the saline continence test in normal controls and in patients with active and quiescent ulcerative colitis

\begin{tabular}{llll}
\hline & & \multicolumn{2}{l}{ Ulcerative colitis } \\
\cline { 2 - 4 } & $\begin{array}{l}\text { Normal } \\
(n=18)\end{array}$ & $\begin{array}{l}\text { Active } \\
(n=17)\end{array}$ & $\begin{array}{l}\text { Quiescent } \\
(n=17)\end{array}$ \\
\hline $\begin{array}{l}\text { Volume infused before first } \\
\text { leak }(\mathrm{ml})\end{array}$ & $1385(350)^{*} \dagger 584(568)$ & $632(488)$ \\
$\begin{array}{l}\text { Volume retained after } \\
\text { infusions of } 1500 \mathrm{ml}(\mathrm{ml})\end{array}$ & $1452(172)^{*}+760(533)$ & $836(483)$ \\
\hline
\end{tabular}

Results are expressed as mean (SD). * significantly different from active colitics; †significantly different from quiescent colitics.

$(614(554) v 110(313) \mathrm{ml}, \mathrm{p}<0.05)$ than those with mildly active colitis. The volume of saline infused before the initial leak $(190(309) \mathrm{ml})$ and the total volume retained $(202(260) \mathrm{ml})$ were both significantly lower in the five patients with active colitis who complained of incontinence compared with active colitics who did not complain of incontinence $(p<0.01, p<0.001)$, quiescent colitics $(p<0.01)$ or normal controls $(p<0 \cdot 001)$. Five minutes after starting the saline infusion, one patient with moderately severe colitis and incontinence felt dizzy. The test was terminated and the patient was excluded from analysis.

\section{Rectal and anal pressure changes during saline infusion}

Within one to two minutes of starting the infusion, all three groups of subjects exhibited a regular pattern of
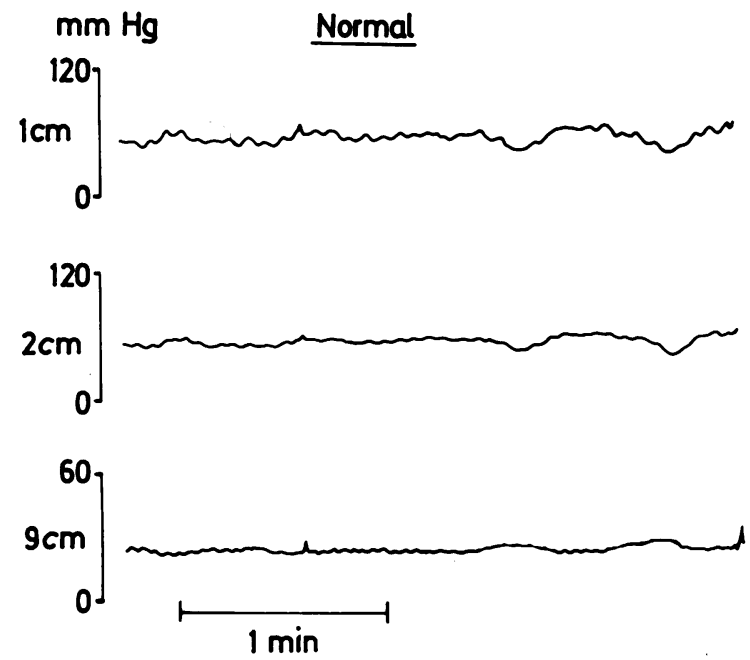

Table 4 Pressure changes in the anal canal $(2 \mathrm{~cm}$ port) and in the rectum ( $9 \mathrm{~cm}$ port) during the first five minutes and last five minutes of saline infusion in normal subjects, in patients with active and quiescent colitis and in active colitics with incontinence

\begin{tabular}{|c|c|c|c|c|}
\hline & $\begin{array}{l}\text { Normal } \\
\text { controls } \\
(n=18)\end{array}$ & $\begin{array}{l}\text { Active colitis } \\
(n=17)\end{array}$ & $\begin{array}{l}\text { sQuiescent } \\
\text { colitis } \\
(n=17)\end{array}$ & $\begin{array}{l}\text { Incontinent } \\
\text { colitis } \\
(n=5)\end{array}$ \\
\hline \multicolumn{5}{|c|}{ First five minutes } \\
\hline Relaxation & $44 \cdot 3(19 \cdot 6)$ & $48 \cdot 8(25 \cdot 8)$ & $42 \cdot 8(23 \cdot 5)$ & $27 \cdot 8(2 \cdot 5)^{*} \dagger \ddagger$ \\
\hline Peak & $121 \cdot 5(42 \cdot 4)$ & $75 \cdot 7(34 \cdot 1)^{*}$ & $67 \cdot 7(27 \cdot 9)^{*}$ & $40 \cdot 4(5 \cdot 9)^{*} \dagger \ddagger$ \\
\hline \multicolumn{5}{|c|}{ Rectal pressures } \\
\hline Basal & $20 \cdot 1(11 \cdot 3)$ & $25 \cdot 4(5 \cdot 7)$ & $23 \cdot 1(6 \cdot 2)$ & $25 \cdot 8(4 \cdot 9)$ \\
\hline Peak & $24 \cdot 3(9 \cdot 4)$ & $34 \cdot 6(8 \cdot 6)^{*}$ & $31 \cdot 1(8 \cdot 8)^{*}$ & $30 \cdot 2(8 \cdot 7)^{*}$ \\
\hline \multicolumn{5}{|c|}{ Last five minutes } \\
\hline Relaxation & $43 \cdot 8(19 \cdot 6)$ & $45 \cdot 3(24 \cdot 2)$ & $38 \cdot 8(14 \cdot 6)$ & $29 \cdot 6(3 \cdot 1)^{*} \dagger \ddagger$ \\
\hline Peak & $116 \cdot 2(35 \cdot 9)$ & $87 \cdot 1(49 \cdot 2)^{*}$ & $71 \cdot 9(29 \cdot 8)^{*}$ & $41 \cdot 4(17 \cdot 5)^{*} \dagger \ddagger$ \\
\hline \multicolumn{5}{|c|}{ Rectal pressures } \\
\hline Basal & $25 \cdot 1(9 \cdot 3)$ & $28 \cdot 8(10 \cdot 8)$ & $26 \cdot 8(10 \cdot 1)$ & $27 \cdot 8(8 \cdot 2)$ \\
\hline Peak & $36 \cdot 7(9 \cdot 4)$ & $48 \cdot 6(18 \cdot 2)^{*}$ & $40 \cdot 8(9 \cdot 1)$ & $.45 \cdot 4(13: 9)$ \\
\hline
\end{tabular}

Results are expressed as mean (SD) $(\mathrm{mmHg}) .{ }^{*}$ significantly different from controls, $\mathrm{p}<0.05$; †significantly different from active colitis, $\mathrm{p}<0.05$; ¥significantly different from quiescent colitis, $\mathrm{p}<0.05$.

oscillations of anorectal pressures consisting of rectal contractions (recorded by all rectal ports) associated with anal relaxations (Figs 3,4). The frequency of these oscillations increased as the infusion progressed but there were no significant differences in frequency between the groups at any stage of the study (Fig. 5). The amplitude of the rectal pressure peaks increased in all the groups as the infusion
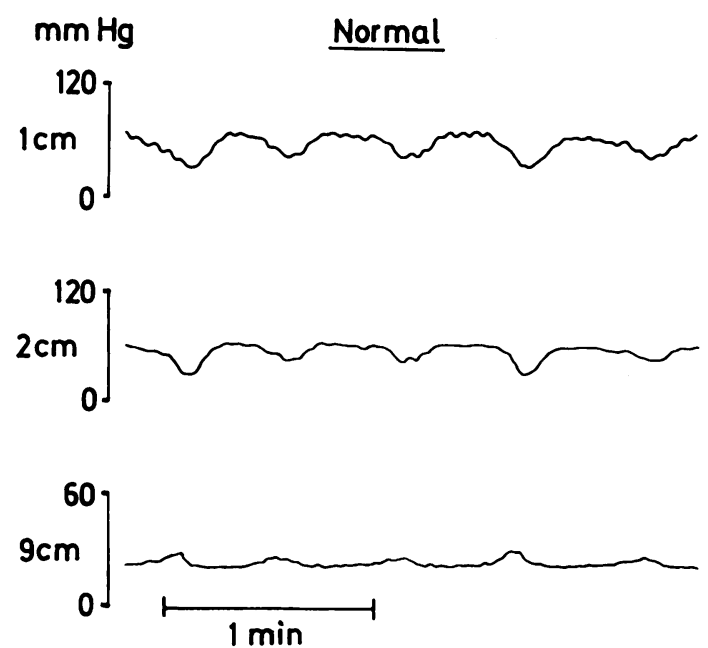

Fig. 3 Typical pattern of phasic rectal contractions and anal relaxations during the first (left) and last (right) five minutes of saline infusion in a normal subject. 

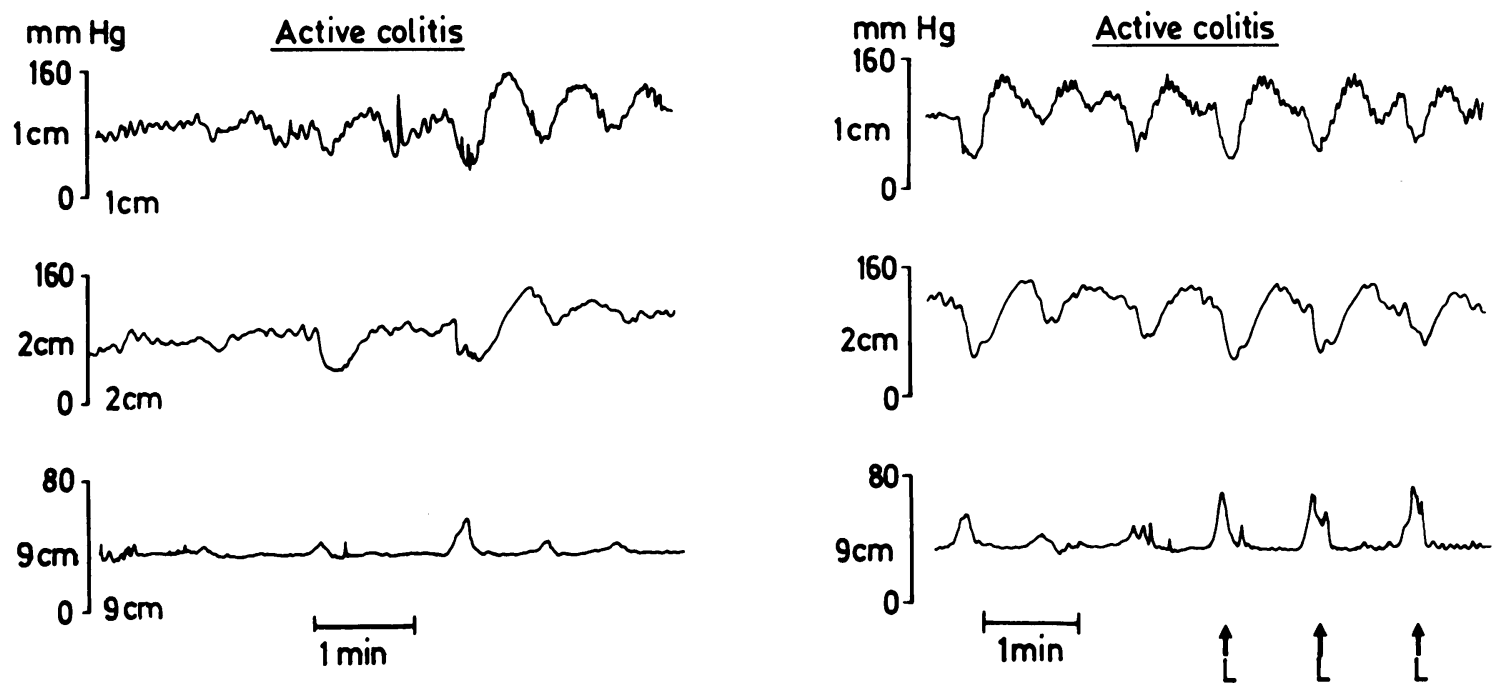

Fig. 4 Typical pattern of the pressure activity during the first (left) and last (right) five minutes of saline infusion in a patient with active colitis showing the large amplitude rectal contractions associated with anal relaxations. $L=$ indicates leakage of saline.

progressed, and was significantly higher in active colitics compared with quiescent colitics $(\mathrm{p}<0.05)$ during the last 10 minutes of infusion and compared with normal controls $(p<0.01)$ at all stages of infusion (Fig. 5). The basal rectal pressures, however, were very similar throughout the infusion.

Anal pressures showed little change as the infusion

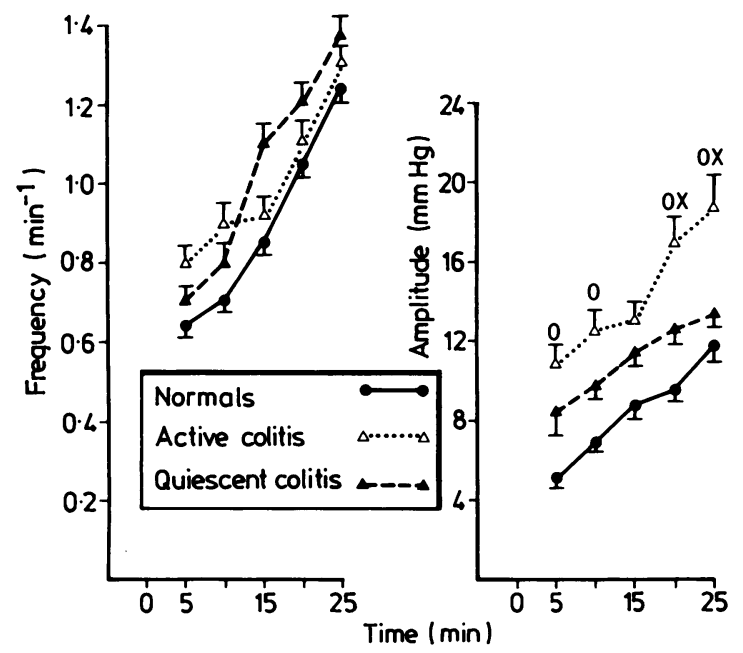

Fig. 5 Mean frequency and amplitude of phasic rectal contractions in sequential five minute periods, during saline infusion. $O=$ significantly different from normal subjects, $p<0 \cdot 05 . X=$ significantly different from quiescent colitis, $p<0 \cdot 05$. progressed, but peak anal pressures were significantly lower throughout the infusion in active colitics and quiescent colitics compared with normal controls (Table 4).

Towards the end of the infusion, the peak rectal pressures exceeded the anal relaxation pressures in eight of $12(67 \%)$ patients with active colitis who did not complain of incontinence, in $13 / 17(76 \%)$ patients with quiescent colitis and in two of $18(11 \%)$ normal controls. Leakage always occurred when the rectal pressures equalled or exceeded the anal pressures (Fig. 6).

Peak and relaxation anal pressures were significantly lower in patients who complained of incontinence compared with the other colitic groups and the normal controls (Table 4) but there were no significant differences in the rectal pressures between the incontinent patients and the other colitic groups. The peak rectal pressures exceeded the anal relaxation pressures throughout the study in the incontinent colitics and leakage occurred at all stages of the infusion (Fig. 6).

Paired results: active $\mathrm{v}$ quiescent disease Remission of disease activity in six patients was associated with significant increases in the total percentage pressure activity in the rectosigmoid region under resting conditions, and in the volume of saline infused before leakage occurred and the total volume of saline retained (Table 5). There were no significant changes in the pattern, frequency or amplitude of rectal contractions during resting con- 


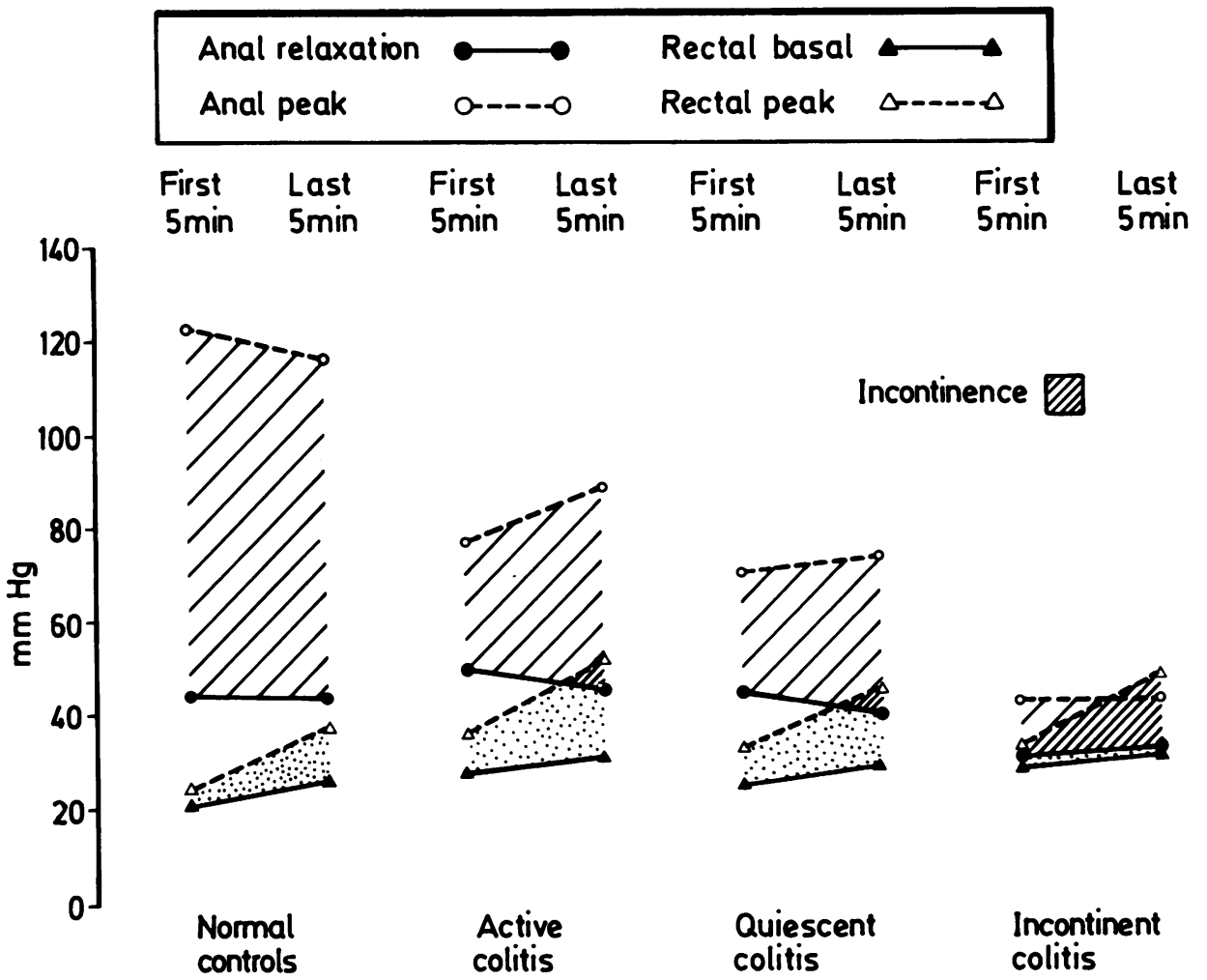

Fig. 6 Anal and rectal pressure changes during the first and last five minutes of saline infusion in normal controls, in patients with active and quiescent colitis and in patients with active colitis and incontinence. The bold hatched areas show the overlap when the rectal peak pressures exceeded the anal relaxation pressures resulting in saline incontinence.

ditions and in the anal or rectal pressures during saline infusion.

\section{Discussion}

Our results showed that despite enormous individual variability in the location, frequency, and incidence of contractions in the rectum, patients with active colitis showed a relative lack of spontaneous rectal contractions compared with quiescent colitics and normal controls. Forty per cent of active colitics exhibited total quiescence in all rectal channels during the one hour basal recording. The incidence of coordinated contractions was also reduced in these patients. Previous studies have reported a reduction of normal contractile activity ${ }^{2-4}$ in patients with active colitis but in two of these studies ${ }^{3+}$ large amplitude propagated rectal contractions were also observed. These observations may be related to the use of large rectal balloons as pressure sensors, as large balloons sample pressures over a longer length of intestine and can detect contractions that do not occlude the lumen. Thus a tandem balloon system is more likely to detect propagating contractions than open tip perfused catheters and to exaggerate their duration and amplitude. Large balloons may also induce the abnormally large rectal contractions in patients with active colitis. We have previously shown that the rectum in active colitis responds to balloon distension with transient increases in pressure that are of particularly high amplitude."

Infusion of saline into the rectum induced a characteristic pattern of regular fluctuations in anorectal pressure, which consisted of increases in rectal pressure accompanied by relaxations in the pressure of the anal canal. ${ }^{12}{ }^{13}$ The frequency and amplitude of rectal contractions were accentuated as the infusion progressed in all subjects, but the increase in amplitude was greater in patients with colitis confirming our previous finding that the colitic rectum is hyper-reactive. ' Enhanced reactivity of the distal colon in active colitis is consistent with our previous observations that transit of ingested radioopaque markers is rapid through the sigmoid colon 
Table 5 Results of the duration of phasic rectal contractions and saline continence in six patients with ulcerative colitis studied during active and quiescent phases

\begin{tabular}{lccc}
\hline & $\begin{array}{l}\text { Active } \\
\text { colitis }\end{array}$ & $\begin{array}{l}\text { Quiescent } \\
\text { colitis }\end{array}$ & $p$ \\
\hline $\begin{array}{l}\text { Duration of activity }(\% \text { of } \\
\text { recording time })\end{array}$ & $13(15)$ & $32(15)$ & $<0.01$ \\
$\begin{array}{l}\text { Volume of saline infused before } \\
\text { first leak }(\mathrm{ml})\end{array}$ & $478(622)$ & $805(547)<0.001$ \\
$\begin{array}{l}\text { Volume retained after infusion of } \\
\quad 1500 \mathrm{ml}(\mathrm{ml})\end{array}$ & $710(510)$ & $1096(412)<0.05$ \\
\hline
\end{tabular}

Results expressed as mean (SD).

and rectum, and that patients with this condition void small volume stools frequently. ${ }^{18}$

There were no significant changes in anal pressures as the infusion progressed, but peak anal pressures were significantly lower in the colitic groups compared with normal controls. As we have previously shown that basal and squeeze sphincter pressures in these patients are similar to those observed in normal controls, ${ }^{7}$ the lower peak anal pressures during saline infusion probably reflects the enhanced anal relaxation to rectal distension, observed in our previous study. ${ }^{7}$ A greater proportion of patients with active colitis leaked saline when compared with normal controls, and leakage always occurred in short spurts when the peak intrarectal pressures exceeded the anal relaxation pressures. In patients with active colitis complaining of incontinence, the peak rectal pressures exceeded the anal relaxation pressures throughout the saline infusion, resulting in a greater degree of leakage during saline infusion than in normal subjects or other groups of colitic patients. Continence to rectally infused saline was also influenced by the severity of inflammation, because patients with mild colitis retained more fluid than patients with moderately severe colitis. The reduction in saline continence in patients with moderately active colitis would explain why such patients often cannot retain steroid enemas. ${ }^{16} 17$

Quiescent colitics exhibited a reduction in saline continence compared with normal controls and showed higher rectal pressures and lower peak anal pressures during saline infusion. Paired studies, however, showed that patients retained more saline when in remission than when their disease was active. These observations indicate that although the abnormal rectal function improves with remission of disease activity, some degree of increased reactivity and irritability persists despite clinical and histological remission.

In conclusion, the combination of a relatively quiescent basal recording, increased rectal tone ${ }^{7}$ and increased phasic pressure responses to distension with saline or balloons suggests that the distal colon in patients with active colitis appears to be tensed and ready to react to intraluminal contents by generating vigorous contractions that challenge the continence mechanism, and cause frequent, urgent and often painful defecation.

Dr S S C Rao is funded by a grant from the Special Trustees for the Former United Sheffield Hospitals. The authors wish to thank Dr W M Sun for his technical assistance.

\section{References}

1 Chaudhary NA, Truelove SC. Human colonic motility: a comparative study of normal subjects, patients with ulcerative colitis and patients with irritable bowel syndrome. I. Resting patterns of motility. Gastroenterology 1961; 40: 1-17.

2 Connell AM. The motility of the pelvic colon. II. Paradoxical motility in diarrhoea and constipation. Gut 1962; 3: 342-8.

3 Spriggs EA, Code CF, Bargen JA, Curtiss RK, Hightower NC. Motility of the pelvic colon and rectum of normal persons and patients with ulcerative colitis. Gastroenterology 1951; 19: 480-91.

4 Kern F Jr, Almy TP, Abbott FK, Bogdanoff MD. The motility of the distal colon in non-specific ulcerative colitis. Gastroenterology 1951; 19: 492-503.

5 Davidson M, Sleisenger MH, Almy PT, Levine SZ. Studies in distal colonic motility in children. I. Nonpropulsive patterns in normal children. Paediatrics 1957; 17: 807-19.

6 Davidson M, Sleisenger MH, Almy PT, Levine SZ. Studies in distal colonic motility in children. II. Propulsive activity in diarrhoeal states. Paediatrics 1957; 17: 820-32.

7 Rao SSC, Read NW, Davison PA, Bannister JJ, Holdsworth $\mathrm{CD}$. Anorectal sensitivity and responses to rectal distension in patients with ulcerative colitis. Gastroenterology. 93: 1270-3.

8 Dinoso VP, Murthy SNS, Goldstein J, Rosner B. Basal motor activity of the distal colon: a reappraisal. Gastroenterology 1983; 85: 637-42.

9 Ritchie JA, Tuckey NS. Intraluminal pressure studies at different distances from the anus in normal subjects and in patients with the irritable colon syndrome. Am J Dig Dis 1969; 14: 96-106.

10 Narducci F, Bassotti G, Gaburri M, Morelli A. Twenty four hour manometric recording of colonic motor activity in healthy man. Gut $1987 ; 28: 17-25$.

11 Snape WJ, Matarazzo SA, Cohen S. Abnormal gastrocolonic response in patients with ulcerative colitis. Gut 1980; 21 : 392-6.

12 Read NW, Haynes WC, Bartolo DCC, et al. Use of anorectal manometry during rectal infusion of saline to investigate sphincter function in incontinence patients. Gastroenterology 1983; 85: 105-13.

13 Haynes WG, Read NW. Anorectal activity in man during rectal infusion of saline: a dynamic assessment of anal continence mechanism. J Physiol 1982; 330: 45-56. 
14 Truelove SC, Witts LJ. Cortisone in ulcerative colitis. Final report on a therapeutic trial. $B r$ Med J 1955; ii: 1041-8.

15 Hancock BD. Measurement of anal pressure and motility. Gut 1976; 17: 645-51.

16 Ruddell WSJ, Dickinson RJ, Dixon MF, Axon ATR. Treatment of distal ulcerative colitis in relapse: comparison of hydrocortisone enemas and rectal hydrocortisone foam. Gut 1980; 21: 885-9.
17 Somerville KW, Langman MJS, Kane SP, MacGilchrist AJ, Watkinson G, Salmon P. Effect of treatment on symptoms and quality of life in patients with ulcerative colitis: comparative trial of hydrocortisone acetate foam and prednisolone 21-phosphate enemas. Br Med J 1985; 291: 866 .

18 Rao SSC, Read NW, Brown C, Bruce C, Holdsworth CD. Studies on the mechanism of bowel disturbance in ulcerative colitis. Gastroenterology. 93: 1(13-9. 